\title{
EDUCAÇÃO INCLUSIVA: TODOS SÃO IGUAIS PERANTE A LEI
}

\author{
Débora Batista*
}

\section{RESUMO}

Compreendemos que uma educação inclusiva de qualidade se faz, dentre outros fatores, valorizando a diversidade e singularidades. Neste artigo, procurarei refletir sobre o cenário educacional, a partir do papel da educação ao longo da história da humanidade e das políticas públicas de inclusão e reformas educacionais. Além de apresentar algumas leis e decretos, contextualizar historicamente. Discutir sobre as práticas pedagógicas atuais, buscando possibilitar a ampliação do debate em torno da inclusão no ambiente escolar.

Palavras-Chave: Educação, Diversidade, Inclusão.

\section{ABSTRACT}

We realize that an inclusive education of quality is made, among other factors, valuing diversity and uniqueness. In this article, we will try to reflect on the educational scene, from the role of education throughout the history of mankind and public inclusion policies and educational reforms. In addition to presenting some laws and decrees, contextualize historically. Discuss current pedagogical practices in order to enable the expansion of the debate on the inclusion in the school environment.

Keywords: Education, Diversity, Inclusion.

*Débora Batista. Pedagoga, Professora da Educação Infantil e mestranda em Educação pela Universidad de la Empresa - UDE. 


\section{INTRODUÇÃO}

Este artigo tem como objetivo discutir a cerca das políticas públicas que norteiam a Educação Inclusiva. Como uma forma de inclusão, a diversidade já tinha sido entendida apesar de ser vista como uma inovação na área de educação especial. Mas cada vez mais, políticas públicas estão sendo feitas para que a educação inclusiva seja compreendida como direito de todos a terem acesso a uma educação de qualidade e igualitária.

\section{Sobre as leis e decretos}

Pessoas com deficiência são aquelas que têm impedimento de longo prazo de natureza física, mental, intelectual ou sensorial, os quais, em interação com diversas barreiras, podem obstruir, sua participação plena e efetiva na sociedade em igualdade de condições com as demais pessoas (Convenção sobre os Direitos das Pessoas com Deficiência, 2007).

Dados do IBGE revelam que $6,2 \%$ da população brasileira tem algum tipo de deficiência. A Pesquisa Nacional de Saúde (PNS) considerou quatro tipos de deficiências: auditiva, visual, física e intelectual.

Dentre os tipos de deficiência pesquisados, a visual é a mais representativa e atinge 3,6\% dos brasileiros, sendo mais comum entre as pessoas com mais de 60 anos $(11,5 \%)$. O grau intenso ou muito intenso da limitação impossibilita $16 \%$ dos deficientes visuais de realizarem atividades habituais como ir à escola, trabalhar e brincar.

O estudo mostra também que $1,3 \%$ da população tem algum tipo de deficiência física e quase a metade deste total $(46,8 \%)$ têm grau intenso ou muito intenso de limitações. Somente $18,4 \%$ desse grupo frequentam serviço de reabilitação.

Ainda segundo o IBGE, 0,8\% da população brasileira tem algum tipo de deficiência intelectual e a maioria $(0,5 \%)$ já nasceu com as limitações. Do total de pessoas com deficiência intelectual, mais da metade $(54,8 \%)$ tem grau intenso ou muito intenso de limitação e cerca de $30 \%$ frequentam algum serviço de reabilitação em saúde.

As pessoas com deficiência auditiva representam 1,1\% da população brasileira e esse tipo de deficiência foi o único que apresentou resultados estatisticamente diferenciados por cor ou raça, sendo mais comum em pessoas brancas $(1,4 \%)$, do que em negros $(0,9 \%)$. Cerca de $0,9 \%$ dos brasileiros ficou surdo em decorrência de alguma doença ou acidente e 0,2\% nasceu surdo. Do 
total de deficientes auditivos, $21 \%$ tem grau intenso ou muito intenso de limitações, que compromete atividades habituais.

Os percentuais mais elevados de deficiência intelectual, física e auditiva foram encontrados em pessoas sem instrução e em pessoas com o ensino fundamental incompleto. A Pesquisa Nacional de Saúde consultou 64 mil domicílios, em 2013.

A diversidade quando é respeitada e discutida na educação e nas organizações, vêm favorecer uma visão dinâmica, contextualizada e plural das identidades, articulando-se as dimensões pessoal e coletiva desses processos. A falta desse respeito pela diversidade traz alguns efeitos negativos, como: a excessiva distância entre suas experiências socioculturais e a escola, baixa autoestima, elevado índice de fracasso escolar, manifestações de desconforto, malestar e agressividade. A educação cada dia mais receberá alunos e profissionais cada vez mais heterogêneos, em termos de raça, etnia, gênero e outros grupos culturalmente diversos. Urge a necessidade da gestão da diversidade no sistema educacional, que proporcione mudanças nos sistemas educacionais, nas organizações, no funcionamento das escolas, nas atitudes práticas dos professores, e nos níveis de relacionamento dos diversos atores sociais.

É de suma importância fazermos uma retrospectiva e uma análise da função social da escola, pois em alguns períodos houveram mudanças significativas. Na década de 1930, o ensino fundamental recebeu status de ensino obrigatório dado pela Constituição Federal de 1934, sendo que a escola pública ampliou consideravelmente a oferta de vagas, ampliação que também atingiu o antigo ensino secundário. No entanto o ensino para pessoas com deficiência não era inerente do Estado e ficava a cargo das instituições privadas.

As escolas se viram superlotadas nas décadas seguintes e por uma diversidade na qual não estavam preparados para atender. Desde aquela época a grande deficiência da educação pública esteve atrelado com a ampliação da oferta sem a devida reestruturação do ensino e a falta de investimento para a formação dos professores, surgindo assim, a evasão escolar e as repetências que constatavam a ineficácia do sistema público.

A LDB 4024/1961 em seu Título X dispôs sobre a educação dos "excepcionais" com a finalidade de integrá-los na comunidade, porém a inclusão deste tema na legislação representou apenas uma estratégia de conciliação entre o clamor da sociedade e a obrigação do Estado.

Para justificar a ineficiência do sistema público de ensino, a LDB 5692/1971 identifica a Educação Especial com as dificuldades de aprendizagem a partir de uma concepção inatista do 
desenvolvimento humano, portanto atribuindo ao indivíduo com deficiência a culpa e a responsabilidade por seu fracasso.

O assunto foi inserido definitivamente com a Constituição de 1988, de forma transversal e abrangente. O direito das pessoas com deficiência à matrícula em classes comuns do ensino regular é amparado no artigo 205 da Constituição Federal, que prevê "a educação como direito de todos, dever do Estado e da família, com a colaboração da sociedade, visando ao pleno desenvolvimento da pessoa, seu preparo para o exercício da cidadania e sua qualificação para o trabalho".

A Carta Magna também garante, no artigo 208, o direito ao atendimento educacional especializado.

Art. 208. III - atendimento educacional especializado aos portadores de deficiência, preferencialmente na rede regular de ensino;

Porém, compete ao Ministério da Educação(MEC) reconhecer, credenciar e autorizar as instituições privadas de educação superior e toda rede federal, e que fica sob a responsabilidade da Diretoria de Políticas de Educação Especial, juntamente com o Ministério Público Federal, o acompanhamento dos procedimentos relativos à recusa de matrícula nessas instituições.

Nas esferas municipal, estadual e distrital, esta competência é das secretarias de educação, que devem fazer a análise e emissão de parecer sobre processos alusivos à recusa de matrícula em instituições escolares, públicas e privadas, sob sua regulação.

Partindo da perspectiva que entende a educação como um complexo processo que não se conclui, para a reflexão sobre educação e diversidade devemos considerar dois aspectos indispensáveis: a) o papel da educação ao longo da história da humanidade e b) as políticas públicas e reformas educacionais. Ao que se refere à história da educação, constata-se que desde a cultura greco-romana, passando pelo renascimento, pelo mercantilismo, iluminismo, modernidade, atravessando o colonialismo até a chegada do capitalismo, o modelo de sistema educativo proposto, independente do modelo econômico vigente, sempre ocupou o papel de veículo para a transmissão da cultura dominante. Esse fato justifica o tipo opressivo de relação e de vínculo entre o indivíduo e a sociedade desde os primórdios da educação até a contemporaneidade. É fato e devemos destacar, de acordo com Espinoza (2002), que inúmeras discussões acerca dessa temática levaram a vários esforços epistêmicos, numa tentativa de reconceitualizar essa concepção, com um enfoque que enfatiza as condições para alcançar 
acordos intersubjetivos quanto a metas emancipatórias da sociedade, ou seja, busca de novas formas de organização social, com uma sociedade mais democrática e menos opressiva.

No entanto, até o momento, é notória a relação de poder do Estado sobre a Educação, com políticas de controle social e, consequentemente, políticas desiguais e insuficientes. Isso quer dizer que para entendermos o processo de política educacional temos que conhecer a relevância do Estado, visto que este se coloca em uma posição de preferência por incrementar os níveis de controle e poder, e não por promover a participação e o acesso igualitário à educação; embora, sempre se apresente com um discurso ideológico de que as políticas públicas educacionais estão a favor da justiça social e da equidade.

Atualmente, temos uma educação com métodos inovadores e mais democrática, porém, menos politizada. Ou seja, uma educação com significativas mudanças, mas que privilegia a forma sobre o conteúdo, sem a lógica da política, mas com a lógica do mercado. Uma educação voltada para formar pessoas socializadas e não para formar cidadãos transformadores e com saberes epistêmicos. Uma educação que trata as pessoas como consumidores e não como cidadãos, que trata as pessoas como militantes de causas políticas e não como ativistas. Esse modelo contraria a postura crítica de Freire (2005), que defende a educação ativa, cooperadora, transformadora e que instiga os alunos a pensar e refletir criticamente.

O Centro Nacional de Educação (CENESP) foi um órgão criado em 1973 para definir metas governamentais para a área, nos quais foram reestruturados ou organizados setores próprios nas secretarias estaduais de educação e nas escolas e definia uma política de formação de professores para a educação especial, que gradativamente perdeu forças políticas e em 1992 foi transformado em Secretaria de Educação Especial (SEESP). Novamente a Secretaria foi extinta e em 2011 passou a compor a Secretaria de Educação Continuada, Alfabetização, Diversidade e Inclusão (SECADI), onde ocupa de modo mais específico a Diretoria de Políticas de Educação Especial.

Ligada inicialmente ao Gabinete Civil da Presidência da República, no mesmo ano foi criada a Coordenadoria para Integração da Pessoa Portadora de Deficiência (CORDE), o órgão foi transferido para vários ministérios até que no ano de 2009, começou a ocupar uma subsecretaria da Secretaria Especial dos Direitos Humanos. Atualmente denominada como Subsecretaria Nacional de Promoção dos Direitos da Pessoa com Deficiência (SNPD), sendo responsável pela articulação e coordenação das políticas nacionais para as pessoas com deficiência. 
Com a Declaração Mundial de Educação para Todos, de 1990, o compromisso com a educação foi reafirmado com a luta pela democratização, independente das deficiências dos alunos: "[...] é preciso tomar medidas que garantam a igualdade de acesso à educação aos portadores de todo e qualquer tipo de deficiência, como parte integrante do sistema educativo" (UNESCO,1990, p.3).

O documento produzido pelos participantes deste encontro ficou conhecido mundialmente como Declaração de Salamanca. A Declaração estabelece que as escolas devem

[...] acolher crianças com deficiência e crianças bem-dotadas; crianças que vivem nas ruas e que trabalham; crianças de populações distantes ou nômades; crianças de minorias linguísticas, étnicas ou culturais e crianças de outros grupos ou zonas desfavorecidas ou marginalizadas (UNESCO, 1994, p.3)

"Os teóricos críticos concordam que as políticas educativas e os movimentos de reforma educacional têm suas origens nas constantes exigências e nas estruturas da economia que serve os interesses da classe dominante que controla e racionaliza o desenvolvimento de novas habilidades e atitudes exigidas pela economia de livre mercado para a sua força laboral" (ESPINOZA, 2002).

Em 2001 o Decreto 3.569 foi promulgado no Brasil, em razão de uma Convenção Interamericana em 1999, mais conhecida como Convenção de Guatemala para a Eliminação de Todas as Formas de descriminação contra as Pessoas Portadoras de Deficiência, diz que pessoas com deficiência não podem receber atendimentos excludentes ou restritivos que Ihes possam dificultar ou impedir o acesso às escolas comuns (BRASIL, 2001).

A Resolução 02 do Conselho da Câmara de Educação Básica (BRASIL, 2001a) proclamou que os sistemas de ensino devem matricular todos os alunos e que o atendimento aos alunos especiais deveria ser realizado em classes comuns. Seria feito em caráter transitório, extraordinário, em razão das necessidades do educando o encaminhamento para as classes e escolas especiais. Porém, o Plano de Educação (PNE) de 2001 não denotou restrição ao uso das classes e escolas especiais pelo sistema educacional (BRASIL, 2001c).

Dados do Censo Escolar realizado pelo INEP indicam crescimento expressivo em relação às matrículas de alunos com deficiência na educação básica regular. Estatísticas indicam que no ano de 2014, 698.768 estudantes especiais estavam matriculados em classes comuns.

O Ministério da Educação (MEC) em 2003, realizou ações transformadoras, onde a educação especial seria uma modalidade transversal do ensino comum, destacando a institucionalização do atendimento educação inclusivo. 
Sendo assim, o Atendimento Educacional Especializado (AEE) foi instituído conceitualmente a partir da publicação do documento Política Nacional de Educação Especial na Perspectiva da Educação Inclusiva (BRASIL, 2008b) onde definia a educação especial como uma parte do ensino comum, perpassando-o em todos os níveis e modalidades.

Dewey nos faz refletir sobre o professor como o agente principal de transmissão do conhecimento e a escola como organização. O professor tem que se preocupar e fazer uma reflexão educacional e pedagógica de suas práticas. Será que ele está atendendo a todos seus alunos? A prática pedagógica deve incluir o indivíduo, com suas singularidades. Quanto a escola, ela precisa mudar institucionalmente. Como organizadora da educação, é de suma importância que além de refletir ela possa ser a base, dar suporte ao professor. A atualização e a produção de novas práticas de ensino só surgem de uma reflexão partilhada entre todos os envolvidos no processo. Essa reflexão, só nasce se houver esforço de encontrar respostas para os problemas educativos enfrentados tanto pelos gestores quanto os professores.

Em 1998, cerca de 200 mil pessoas estavam matriculadas na educação básica, sendo apenas 13\% em classes comuns. Em 2014, eram quase 900 mil matrículas e 79\% delas em turmas comuns.Se considerarmos somente as escolas públicas, o percentual de inclusão sobe para 93\% em classes comuns.

\section{CONSIDERAÇÕES FINAIS}

Neste artigo apresentei alguns fatos e evoluções da história da educação inclusiva no Brasil. Como vimos, os dados do último senso nos mostra avanços nas matrículas de alunos especiais nas classes comuns, porém, inclusão é muito mais do que ter alunos com necessidades especiais dentro de uma sala de aula. Incluir estes alunos é ter competências e habilidades nas quais gestores, professores e sociedade tem que estar comprometidos de verdade com a causa. São muitas as leis, decretos, portarias e resoluções que nos mostram que é direito de todos terem uma educação de qualidade e inclusiva independente de suas singularidades.

Infelizmente, as leis não são cumpridas e efetivadas dentro mesmo daquela deveria ser promotora de aprendizagem e do pleno desenvolvimento dos seres humanos, a escola. Antes de qualquer diferença física e/ou intelectual somos todos iguais perante a lei. E por isso, temos todos os mesmos direitos e deveres a serem cumpridos. 
É um desafio e tanto para as escolas nos dias de hoje onde leis estão cada vez mais inclusivas, pais participativos que brigam por seus direitos e nela nada muda. Sem infraestrutura, sem material adaptado e o principal, professores desqualificados e sobrecarregados com turmas superlotadas.

Cabe a reflexão de que sem mudança na prática dentro de uma sala de aula e seu entorno, a escola não estará cumprindo o seu papel. E as exclusões continuarão.

\section{Referências}

BRASIL. Câmara dos Deputados.Centro de Documentação e Informação. Lei N. 4.024. Fixa as Diretrizes e Bases da Educação Nacional. Brasília: CD/CDI, 1961.

BRASIL. Constituição da República Federativa do Brasil. Brasília, DF, 1988.

BRASIL. Conselho Nacional de Educação. Câmara de Educação Básica. Resolução n.02, de 11 de setembro de $2001^{\mathrm{a}}$. Diário oficial da União, Brasília, 14 de setembro de 2001 . Seção 1E, p. $39-40$

BRASIL. Decreto $\mathbf{N}^{\circ}$ 3.596, de 8 de outubro de 2001b. Disponível em: http://www.planalto.gov.br/ccivil 03/decreto/2001/d3956.htm.

BRASIL. Lei n. 10.172, de 09 de janeiro de 2001c. Estabelece o Plano Nacional de Educação. Diário Oficial da União, Brasília, 10 de janeiro de 2001.

BRASIL. Ministério da Educação. Secretaria de Educação Especial. Decreto n. 6.571, de 17 de setembro de 2008. Brasília: MEC/SEESP, 2008a.

BRASIL. Ministério da Educação. Secretaria de Educação Especial. Política Nacional de Educação Especial na Perspectiva da Educação Inclusiva. Brasília: MEC/SEESP, 2008b. Disponível em: http://portal.mec.gov.br/arquivos/pdf/politicaeducespecial.pdf.

BRASIL. Ministério da Educação. Conselho Nacional de Educação. Câmara de Educação Básica. Resolução n. 04, de 02 de outubro de 2009. Diário Oficial da União. Brasília, 05 de outubro de 2008, Seção 1, p. 17. 
BRASIL. Ministério da Educação. Secretaria de Educação Especial. Nota Técnica n. 9/2010, de 09 de abril de 2010. Brasília: MEC/SEESP, 2010a. Disponível em: www.mec.gov.br/seesp

BRASIL. Ministério da Educação. Secretaria de Educação Especial. Nota técnica n. 11/2010, de 07 de maio de 2010. Brasília: MEC/SEESP, 2010b. Disponível em: www.mec.gov.br/seesp

BRASIL. Decreto No7611, de 17 de novembro de 2011 a . Disponível em: http://www.planalto.gov.br/ccivil 03/ Ato2011-2014/2011/Decreto/D7611.htm

BRASIL. Câmara dos Deputados. Projeto de Lei do Plano Nacional de Educação (PNE 20112020). Brasília: Edições Câmara, 2011b. Disponível em: http://bd.camara.gov.br/

BRASIL. Fundo Nacional de Educação de Desenvolvimento da Educação. Resolução n.27, de 02 de junho de 2011c. Diário Oficial da União, Brasília, 03 de junho de 2011. Seção 1, p. 351

BRASIL. Ministério da Educação. Secretaria de Educação Continuada, Alfabetização, Diversidade e Inclusão. Diretoria de Políticas de Educação Especial. Nota técnica n. 62/2011, de 08 de dezembro de 2011d. Brasília: MEC/SECADI/DPEE, 2011.

BRASIL. Ministério da Educação. Instituto Nacional de Estudos e Pesquisas Educacionais Anísio Teixeira. Sinopse Estatística da Educação Básica. 2013.

DEWEY, John. Como Pensamos. São Paulo: Companhia Editora Nacional, 1959.

DEWEY, John. Democracia e Educação. Introdução à Filosofia da Educação. 4. ed. São Paulo: Companhia Editora Nacional, 1979.

ESPINOZA, O. La relación Estado-educación y el proceso de reforma educacional: una aproximación desde la teoría crítica. Revista Iberoamericana de Educación, n. 45/1 - 25 de janeiro de 2008.

FREIRE, P. Pedagogia da autonomia: saberes necessários à prática educativa. São Paulo: Paz e Terra, 2010.

UNESCO. Declaração de Salamanca. Salamanca, Espanha, 1994. Disponível em: http://portal.mec.gov.br/seesp/arquivos/pdf/salamanca.pdf 
UNESCO. Salamanca - cinco años después. Una revisión de las actividades de UNESCO a la luz de La Declaración y el marco de acción de Salamanca. 1999a.Disponível em: http://unesdoc.unesco.org/images/0011/001181/118118so.pdf

UNESCO. La participación en la educación para todos: la inclusión de alumnos con discapacidad. Boletín EFA 2000, 1999b. Disponível em:http://unesdoc.unesco.org/images/0017/001778/177849s.pdf 